\title{
Atribuição de significado à escrita, por crianças surdas usuárias de língua de sinais
}

\section{Meaning assignment to writing by deaf children who are users of sign language}

\author{
Tânia dos Santos Alvarez da Silva ${ }^{1}$ \\ Maria Augusta Bolsanello ${ }^{2}$
}

\begin{abstract}
RESUMO
O artigo identifica orientações distintas presentes nas proposições metodológicas de ensino da escrita para surdos usuários de língua de sinais, assumidas na educação bilíngue. Assim, apresenta duas formas de interpretação e encaminhamento de proposições metodológicas de orientação bilíngue, em relação ao ensino da escrita pelo surdo. O primeiro grupo de autores defende que o surdo deve aprender o português escrito tendo a língua de sinais como língua base. O segundo grupo, fundamentado em pesquisas da neuropsicologia cognitiva, defende que a escrita dos sinais, que deve ser a primeira língua escrita de aprendizes surdos sinalizadores. Conclui-se que as duas orientações sobre as possíveis relações entre o surdo e a escrita não devem ser tomadas como posições excludentes. Pelo contrário, sugere-se que a escrita dos sinais, enquanto um sistema simbólico repleto de significados, constitui-se como ferramenta eficiente para maximizar o desenvolvimento das funções psicológicas superiores dos aprendizes surdos, bem como para fornecer meios de aproximação com o sistema de escrita alfabética.
\end{abstract}

Palavras-chave: crianças surdas; língua de sinais; escrita de sinais; aquisição da escrita.

DOI: $10.1590 / 0104-4060.37020$

1 Universidade Estadual de Maringá. Maringá, Paraná, Brasil. Departamento de Teoria e Prática da Educação. Avenida Colombo, 5790. CEP: 87020-900.

2 Universidade Federal do Paraná. Curitiba, Paraná, Brasil. Setor de Educação. Rua General Carneiro, 460. CEP: 80060-150. 


\begin{abstract}
This article identifies distinct guidelines on methodological propositions of the writing teaching for deaf users of sign language, which are assumed in bilingual education. So, it presents two forms of interpretation and routing of methodological propositions of bilingual orientation, in relation to the writing teaching by the deaf. The first group of authors defends that the deaf must learn written Portuguese having sign language as the base language. The second group, based on researches about cognitive neuropsychology, defends that SignWriting must be the first written language of deaf sign apprentices. We concluded that both orientations about the possible relations between the deaf and writing mustn't be taken as excluding positions. On the contrary, it is suggested that SignWriting, as a symbolic system full of meanings, is an efficient tool to maximize the development of higher psychological functions of the deaf apprentices, as well as to provide means of approximation with the system of alphabetic writing.
\end{abstract}

Keywords: deaf children; sign language; SignWriting; writing acquisition.

Dentre as produções científicas acerca da apropriação da escrita pelo surdo, destacam-se duas orientações pedagógicas que se propõem a discutir e apontar caminhos para o ensino da escrita ao surdo. Cada uma delas busca, por um lado, identificar os caminhos que levam o surdo a aproximar-se da escrita e, por outro lado, defender encaminhamentos pedagógicos para a educação dessa minoria linguística. Estas duas orientações, embora se aproximem em essência, possuem em si diferenças marcantes para o ensino da escrita advindas do bilinguismo.

$\mathrm{Na}$ primeira orientação, reúnem-se autores que defendem o ensino da escrita do Português para o surdo, tendo a língua de sinais como língua base (FERNANDES, 2003; GESUELI; GÓES, 2001; BOTELHO, 1998; FREIRE, 1999; KARNOPP, 2004; COSTA, 2003; BROCHADO, 2003).

A segunda orientação, fundamentada em pesquisas da neuropsicologia cognitiva, sugere o ensino da escrita visual direta dos sinais, sistema conhecido de forma abreviada como escrita dos sinais, como primeira língua escrita de aprendizes surdos sinalizadores (CAPOVILLA; RAPHAEL, 2001; STUMPF, 2004; SILVA, 2008; WANDERLEY, 2012).

O presente artigo busca analisar e tecer considerações sobre estas duas orientações de caráter bilíngue. 


\section{O ensino da escrita do português para o surdo alicerçado na Língua Brasileira de Sinais}

Na defesa do uso da língua de sinais como língua ideal para dar sustentação a toda atividade intelectual de sujeitos surdos, os adeptos dessa orientação defendem que é possível, por meio de práticas pedagógicas de letramento, levar o aluno surdo a apropriar-se da língua portuguesa escrita, em toda a sua complexidade, sem recorrer à oralidade. Entende-se que a língua de sinais é a língua acessível ao surdo por não impor a este obstáculos sensoriais e poder ser adquirida por imersão linguística em ambiente adequado, ou seja, na convivência espontânea com usuários dessa modalidade linguística. Por tal raciocínio, só a língua de sinais é capaz de aproximar o surdo da escrita da língua portuguesa, conferindo-lhe a adequada significação (KARNOPP, 2004).

Para Fernandes (2003, p. 49), a construção de uma educação bilíngue para alunos surdos, que para ela consiste em assumir o ensino do português na modalidade escrita como segunda língua, poderia representar uma estratégia para “[...] reverter práticas de exclusão, rejeição, preconceito e marginalização a que os surdos estiveram relegados, historicamente". A autora sugere o ensino da língua portuguesa escrita para o surdo por meio de estratégias já conhecidas e empregadas no ensino de línguas estrangeiras para o ouvinte, mais pontualmente aquelas que privilegiam o aspecto visual. Na situação particular dos surdos, tais estratégias se apoiariam seguramente na língua de sinais.

Gesueli e Góes (2001) desenvolveram um estudo longitudinal com crianças com surdez profunda, de idades entre 5 e 6 anos, focado sobretudo no ensino inicial da leitura e da escrita. Destacaram a capacidade exibida pelas crianças de se apoiarem na língua de sinais para se relacionarem com o português escrito. Assim, afirmam: “[...] chama a atenção o fato de que as crianças 'transitam' da língua de sinais para a escrita e vice-versa, numa elaboração dinâmica, em que os sinais permitem significar as possibilidades de registro do Português escrito" (GESUELI; GÓES, 2001, p. 5). As autoras destacam ainda que crianças surdas sinalizadoras orientam sua relação com a escrita tendo por suporte a língua de sinais, que permite a "[...] interpretação do registro visual escrito" (p. 6).

Ao refletir sobre as particularidades do aprendizado da língua escrita por crianças ouvintes e surdas, Fernandes (2003) afirma se tratar de processos com características bastante distintas. Pela mediação de leitores experientes, a criança ouvinte estabelece relações significativas entre oralidade e representação escrita das palavras. Assim, torna-se capaz de evocar o som - e o significado de palavras e sentenças ao perceber visualmente a escrita. No caso da criança surda, 
o domínio da língua escrita ocorre pelo canal visual. Ela percebe visualmente um determinado símbolo gráfico que a remete à recuperação mental do sinal também visual, em Libras, e este, por sua vez, permite significar a palavra escrita.

Na mesma direção, Gesueli e Góes (2001) argumentam que a capacidade observada em crianças ouvintes de perceber, por meio de pistas visuais e sem a interferência direta do adulto, letras ou pedaços de palavras que estão contidos em palavras maiores, apresenta-se de modo mais aguçado na criança surda.

Para Fernandes (2003), o surdo se apropria da língua portuguesa escrita não como um sistema alfabético, mas como um sistema ideográfico, ao qual atribui significado. A autora sugere a observação de cinco aspectos necessários à organização de um planejamento de ensino que pretenda desenvolver competências de leitura e produção escrita com surdos, a saber: (a) contextualização visual do texto; (b) leitura do texto em Libras (ativação do conhecimento prévio de elementos lexicais, gramaticais e intertextuais); (c) percepção de elementos linguísticos significativos, com funções importantes no texto, relacionados à sua tipologia e estilo/registro; (d) leitura individual/verificação de hipóteses de leitura; (e) re-elaboração escrita com vistas à sistematização de aspectos estruturais (FERNANDES, 2003, p. 150-151).

Algumas inferências de Gesueli e Góes (2001), possibilitadas pela análise dos dados coletados na pesquisa que desenvolveram acerca da escrita inicial da criança surda, merecem destaque:

a) Palavras que em Libras se associam ao alfabeto digital, com configuração de mão correspondente à inicial do vocábulo em português, permitiram desencadear nas crianças observadas a recuperação mental da pista fornecida por sua língua de uso. Assim, quando solicitadas, as crianças registraram corretamente a inicial das palavras que se enquadravam na referida condição;

b) De forma semelhante ao que é feito pela criança ouvinte, a criança surda, em seus ensaios de produção de escrita, tende a utilizar as letras que conhece bem (geralmente as letras do próprio nome) para compor diferentes palavras, ainda que essas letras não representem, pelos padrões convencionais, as palavras pretendidas;

c) Por vezes, o emprego de letras é substituído por números, quando esses, no julgamento da criança, representam melhor a ideia que ela pretende registrar. Como exemplo, as autoras destacam o emprego do número 7 por duas crianças, precedendo as letras selecionadas para a escrita da palavra ANÃO. O símbolo datilológico A aparece na composição do sinal da palavra anão, em Libras. Contudo, há indícios de que o número 7, em razão do contato com a história "Branca de Neve e os sete anões", foi mais significativo para a representação do que a letra inicial; 
d) Crianças que desenvolveram algumas técnicas de leitura labial ou de oralização utilizam tais recursos de forma complementar às tentativas de escrita, mas não como recurso principal.

Botelho (1998), por sua vez, investigou a competência em leitura e escrita de uma população de jovens surdos. Sua amostra era subdividida em sujeitos oralizados e em usuários de Libras. A metodologia empregada consistiu no trabalho de leitura, interpretação e reconstrução escrita de três textos. Os resultados alcançados evidenciaram que embora os surdos oralizados obtivessem um melhor desempenho na escrita (sintaxe, ortografia), em conteúdo as produções dos surdos usuários de Libras foram superiores.

Reafirmando sua convicção de que o bilinguismo se constitui como um caminho eficaz para levar estudantes surdos a alcançarem bom desempenho em leitura e escrita, Botelho (1998) cita a Dinamarca e a Suécia como exemplos de países bem-sucedidos na condução dessa filosofia de ensino. A autora revela que desde o início da década de 1980 esses dois países adotaram, com sucesso, a filosofia bilíngue na educação de pessoas surdas. Para ela, adotar atitudes de valorização da leitura e da escrita, como fez a Suécia, é determinante para a formação de leitores e escritores competentes.

Freire (1999) apresenta uma proposta de reestruturação curricular para o Instituto Nacional de Educação de Surdos (INES) tendo por meta a superação dos problemas de aprendizagem de leitura e escrita, tão presentes na formação escolar do alunado surdo. Tal proposta resultou da necessidade de que o INES apontasse soluções para o insucesso vivenciado pelos surdos em suas histórias de escolarização, particularmente nas vivências com a língua escrita. Metodologicamente assumiu-se a condução do ensino de português escrito como segunda língua, focando a leitura e a produção escrita sem recorrer à oralidade. A orientação central apresentada por Freire (1999) consiste no reconhecimento da língua de sinais como primeira língua, por meio da qual todos os conteúdos escolares seriam, necessariamente, trabalhados e, ainda, como suporte necessário à aprendizagem da língua portuguesa escrita como segunda língua. A referida autora entende que a competência comunicativa do sujeito, determinada pelos conhecimentos sistêmico, de mundo e de organização textual, está sempre ancorando seu movimento de significação de novos conteúdos. Decorre daí a necessidade de explicitar e alinhavar, ao longo das atividades de ensino, os elementos que definem a competência comunicativa do sujeito.

Para Costa (2003), ao escrever a língua portuguesa, o surdo se apoia em sua língua de sinais ou no que ela denomina "[...] língua utilizada na comunicação face a face" (COSTA, 2003, p. 99). Esse mecanismo, segundo a autora, faz com que o português escrito pelo surdo assuma estrutura sintática semelhante à estrutura de sua língua de uso; contudo, à medida que o surdo tem acesso 
ao ensino do português escrito, as marcas da primeira língua tendem a ceder espaço para a estruturação adequada da escrita em português. Para ilustrar sua tese, Costa (2003) cita a pesquisa desenvolvida por Valentine (1995) sobre a apropriação da escrita por surdos em rede telemática. Tal pesquisa procura demonstrar que a escrita do português pelos surdos passa por três estágios: o do emprego indiscriminado da sintaxe da Libras, um estágio intermediário, no qual as estruturas das duas línguas se alternam, e o estágio final, quando a estrutura do português prevalece.

Brochado (2003), investigando crianças surdas pré-linguais, filhas de pais ouvintes, concluiu que as mesmas se mostraram capazes de se apropriar do português escrito sem passar pela oralidade. Para o desenvolvimento de seu estudo, Brochado (2003, p. 312) adota o conceito de interlínguas e, dessa forma, pressupõe "[...] a existência de uma estrutura psicológica latente no cérebro que é acionada no processo de aprendizagem de L2." Por tal entendimento, o aprendiz é capaz de melhorar seu desempenho na segunda língua (L2) à medida que se apropria das regras próprias dessa língua-alvo, explicitadas por meio do emprego da primeira língua (L1). A autora destaca ainda que os surdos, embora possam alcançar níveis eficientes de uso do português escrito, sempre serão estrangeiros no uso do Português, embora muitas de suas construções sejam próximas das de um falante não nativo.

Já Sanches (2014) considera que os benefícios resultantes do ensino da escrita do português pelo surdo decorrem da aproximação entre língua de sinais e escrita lexical do português. A pesquisadora afirma que os alunos surdos que aprendem por essa perspectiva metodológica apresentam ganhos que não se restringem à conquista do sistema de escrita do português, mas que tal proposta permite também ampliar conhecimentos em língua de sinais, bem como em conhecimento de mundo.

Neste contexto também não se pode deixar de citar Vygotsky (1997), para o qual o ensino da escrita precisa superar os aspectos meramente técnicos e enfatizar o uso racional do sistema de escrita. É preciso que a condução do ensino da língua escrita se converta, verdadeiramente, para o aprendiz, na apropriação de um sistema completo de linguagem. Tal sistema é, para a criança ouvinte, inicialmente, uma forma indireta de simbolização, pois pela escrita a criança evoca os sons das palavras, que, por sua vez, simbolizam os objetos e fatos do mundo real. À medida que ela passa a dominar plenamente o sistema da escrita, este se converte em um simbolismo de primeira ordem, já que passa a remetê-la diretamente aos significados do mundo real. O percurso para a criança surda chegar ao domínio da escrita, acredita Vygotsky, é bastante diferente daquele experimentado pela criança ouvinte. Da mesma forma, a função assumida pelo sistema da escrita possui características marcadamente distintas. 
Em alguns aspectos, Vygotsky (2001) fornece argumentação teórica que confirma as proposições dos autores que defendem o ensino da escrita do português para o surdo alicerçado na Libras, particularmente no que se refere à possibilidade de conduzir o ensino da escrita de forma independente da oralidade. Assim, Vygotsky, que já em 1930 assumira a defesa da necessidade de a educação de surdos recorrer à língua de sinais para assegurar o desenvolvimento adequado da linguagem e do pensamento das crianças surdas, em 1931 sugere a apropriação da escrita pela criança surda como simbolismo de primeira ordem, ou seja, que a escrita do surdo não deveria se apoiar na língua oral. Antes, por meio do aprendizado da escrita, a criança surda deveria sistematizar sua linguagem. Dessa forma, a escrita representaria para a criança surda o que a oralidade representa para a ouvinte. Para o autor, essa apropriação é possível por ser a escrita um sistema de linguagem com características próprias, e não necessariamente dependente da oralidade.

\section{O ensino da escrita dos sinais como primeira língua escrita de alunos surdos sinalizadores}

Em contraponto à orientação que defende o ensino da escrita do português para o surdo, alicerçada na língua de sinais, tem-se a segunda orientação que sugere o ensino da escrita dos sinais como primeira língua escrita de alunos surdos sinalizadores.

Educadores respaldados em resultados de pesquisas da neuropsicologia cognitiva sugerem que a Escrita dos Sinais, internacionalmente conhecida como sistema SignWriting, é uma alternativa viável para que os surdos possam dominar, efetivamente, um sistema de escrita significativo para eles. Defendem que "[...] o bilinguismo é mais pleno quando permite aos surdos aprender a ler e escrever nas duas línguas: a Libras, por meio de sistemas visuais diretos como SignWriting, e o Português, por meio da escrita alfabética tradicional" (CAPOVILLA; RAPHAEL, 2001, p. 33).

O SignWriting cada vez mais é utilizado em pesquisas e em alfabetização/ letramento de pessoas surdas, segundo o site SignWriting (www.signwriting.org). Marianne Rossi Stumpf, pesquisadora surda brasileira, define as características fundamentais do sistema SignWriting:

O sistema SignWriting que representa as unidades gestuais fundamentais, suas propriedades e relações, tem como ponto de partida a língua de 
sinais dos surdos. É um sistema notacional de características gestuais das línguas de sinais. Ele representa unidades gestuais, e não unidades semânticas, por isso pode ser aplicado a qualquer língua de sinais dos surdos. Na verdade já é usado em mais de 30 países (STUMPF, 2004, p. 147).

A criança ouvinte, em seus contatos iniciais com a língua escrita, formula hipóteses sobre as relações existentes entre as palavras ouvidas e os símbolos gráficos que as representam. Para Capovilla e Raphael (2001), esse período de descobertas e estabelecimento de relações tem seu ápice no momento em que, apoiada por um mediador competente, a criança chega ao estágio alfabético do desenvolvimento da escrita e passa a buscar para cada fonema o grafema correspondente. O domínio do sistema alfabético permite ao seu usuário a representação e a leitura de palavras conhecidas, bem como de palavras desconhecidas ou inventadas. Por essa via, a criança brasileira descobre que o português escrito representa a pauta sonora da língua portuguesa oral, de tal modo que cada som emitido pelos órgãos fonadores pode ser representado por um ou mais grafemas que, combinados, representam palavras, frases, textos - enfim, ideias.

[...] a escrita alfabética do Português permite à criança ouvinte ler por ecodificação grafofonêmica, já que o alfabeto é feito para transcrever os sons da fala. Decodificando, isto é, ampliando as regras de correspondência entre grafemas e fonemas, a criança ouvinte consegue converter o texto em fala. Como a mecânica da leitura alfabética consiste na conversão de letras em sons, ela evoca diretamente os sons das palavras faladas com que a criança ouvinte pensa e se comunica. Assim, a escrita alfabética é um veículo muito eficaz do pensamento do ouvinte (CAPOVILLA; RAPHAEL, 2001, p. 1497).

Os pesquisadores envolvidos com a sistematização do SignWriting para a Libras defendem a ideia segundo a qual a escrita alfabética, sistema próprio para a representação escrita das línguas orais, é inadequada para a criança surda usuária de língua de sinais, pois, para dominá-la, precisaria se submeter à memorização mecânica das inúmeras combinações possíveis das letras que compõem as palavras em diferentes textos e contextos. "Como a mecânica do código (alfabético) só é capaz de produzir a fala interna, mas não a sinalização interna, a escrita acaba consistindo, para o surdo, num agregado complexo e mudo de traços visuais, cuja relação arbitrária com as coisas precisa ser aprendida 
por memorização descontextualizada e artificial" (CAPOVILLA; RAPHAEL, 2001, p. 1498). Os autores prosseguem explicando o desempenho insuficiente da comunidade surda escolarizada em leitura alfabética:

Só quando os sinais lexicais de sua língua puderem ser produzidos naturalmente pela atividade de leitura, assim como as palavras da língua falada são produzidas naturalmente pela escrita alfabética do ouvinte, é que o Surdo poderá prescindir da necessidade de memorizar um número constrangedor de relações arbitrárias que, pelo próprio tamanho, embota o desenvolvimento médio de leitura, limitando-o ao nível da quinta série do ensino fundamental (CAPOVILLA; RAPHAEL, 2001, p. 1506).

Por entenderem que a escrita deve ser para seu usuário uma ferramenta eficiente para a representação do pensamento e das mais diversas informações, os autores sintonizados com as pesquisas da neuropsicologia cognitiva defendem que esta deve estar estreitamente relacionada com a forma pela qual o sujeito processa as informações.

Não obstante, considerando as inúmeras dificuldades de apropriação pelo surdo tanto de uma língua oral quanto de um sistema escrito de representação de sons da fala como primeira língua escrita, Capovilla e Raphael (2001) sugerem que ao surdo seja propiciada a escrita de sua própria língua. Para eles, o sistema SignWritting se apresenta como um instrumento a serviço do funcionamento cognitivo do surdo, de tal forma que este pode se beneficiar da representação escrita de sua língua da mesma forma que o ouvinte se beneficia da escrita alfabética. Assim, para alcançar a escrita do português, o surdo teria como conhecimento de base uma primeira língua escrita: a escrita dos sinais. O aprendizado do português escrito seria, então, um objetivo posterior a ser alcançado na educação dos surdos. O objetivo imediato, por essa argumentação, seria o aprendizado da representação escrita da Libras.

Uma parte expressiva da comunidade acadêmica ligada à surdez acaba se contentando com avanços insuficientes na educação de sujeitos surdos, de acordo com Stumpf (2004). Entre as condutas adotadas que podem ser computadas como ganhos, mas que no entendimento da autora não respondem integralmente às necessidades da comunidade surda, destacam-se: a adoção precoce da língua de sinais na educação das crianças surdas em processo de escolarização; a habilitação em língua de sinais dos professores ouvintes que atuam na área da surdez e, finalmente, a adequação de metodologias visando ao ensino do português escrito para estudantes surdos. 
Stumpf (2004) salienta também que a educação dos surdos carece da implementação de condutas verdadeiramente transformadoras. Suas proposições estão pautadas no entendimento de que, tal como preconizam as "[...] investigações psicogenéticas do aprendizado da escrita e da leitura" (STUMPF, 2004, p.143), a criança precisa assumir um papel ativo em seu processo de aprendizagem. Em relação ao ensino da leitura e escrita, a autora é incisiva em afirmar que a primeira língua escrita da criança surda deve ser a escrita dos sinais, ou seja, a representação escrita dos sinais de sua língua. Ela reconhece também a necessidade do aprendizado da língua escrita majoritária do país como recurso para o surdo melhor exercer suas atividades profissionais e sociais. No entanto, insiste que o aprendizado de uma segunda língua pelo surdo deve ter por suporte o aprendizado de sua própria língua escrita.

Para Stumpf (2004), a capacidade de leitura e escrita confere ao sujeito a possibilidade de reflexão até mesmo sobre a própria língua. A pesquisadora adverte sobre a necessidade de as escolas de surdos contemplarem o ensino do SignWriting em seus currículos. Além de entender que a escrita dos sinais se constitui em um importante instrumento para o acesso ao conhecimento e para a organização do pensamento do surdo, a pesquisadora afirma que o domínio desse sistema de escrita facilita ao surdo o aprendizado do português escrito: "A aquisição da escrita em sinais vai funcionar como suporte para a aprendizagem do português escrito" (p. 158).

Stumpf (2004) relata uma investigação realizada com alunos surdos da $2^{\mathrm{a}}$ série do ensino fundamental na qual desenvolve um projeto de alfabetização pelo sistema de escrita dos sinais. Neste projeto, as aulas de escrita dos sinais eram ministradas em momentos específicos, duas vezes por semana, tendo cada aula a duração de uma hora, aproximadamente. Materiais escritos coletados nas referidas aulas revelam tentativas espontâneas dos alunos de representar em sinais o conteúdo de histórias que lhes haviam sido contadas em Libras pela professora. Para Stumpf(2004), crianças usuárias de Libras, mesmo imersas em um programa de alfabetização em português, tendem, em suas tentativas iniciais de escrita, a representar graficamente sua língua de sinais. “[...] a criança está sendo alfabetizada em português, mas representa também sua língua de sinais de uma forma espontânea" (p. 152).

$\mathrm{Na}$ condução do projeto de escrita dos sinais, as crianças são postas em contato com o sistema SignWriting por meio de legendas de fotos, livros infantis já traduzidos e jogos de dominó, em que elas precisam unir o objeto à escrita no sistema em aprendizagem, ou ainda registrar em escrita dos sinais diálogos estabelecidos em Libras. Num momento inicial, as crianças aprendem a escrever de forma manuscrita os símbolos gráficos da escrita dos sinais. O passo seguinte é usar no computador o programa Sign Writer. 
Aprender a forma manuscrita da escrita de sinais é, em certo sentido, uma aprendizagem relativamente difícil e desafiadora, em razão de esse sistema ser restrito ao espaço de sala de aula. O traçado do sistema alfabético se torna menos penoso, provavelmente, por causa da familiaridade que, desde muito cedo, a criança estabelece com ele, por meio da ostensiva exposição a materiais escritos: placas, outdoors, panfletos, livros, revistas, jornais, propagandas em TV, entre outros. Para Stumpf (2003), a despeito da dificuldade inicial experimentada no traçado da escrita dos sinais, tal aprendizado oportuniza a reflexão sobre a adequada configuração de mão necessária à produção de cada sinal. Isso porque o sistema representa os diferentes sinais que compõem as línguas de modalidade espaço-visual, exigindo, para sua escrita, precisão na representação da fonologia própria da língua.

Stumpf (2004) julga ainda que a criança surda manifesta certa tendência a representar sua língua de sinais por meio do registro do movimento. É importante observar que as crianças por ela observadas eram participantes do projeto de leitura e escrita no sistema SignWriting. Dessa forma, o contato com tal sistema de escrita pode ter sido responsável por impulsionar as manifestações observadas pela pesquisadora.

Silva (2008), por sua vez, pesquisando o processo de aquisição da escrita por crianças surdas, de idades entre 4 e 8 anos, usuárias da Libras, observou que crianças surdas que não dominam a escrita alfabética tenderam a representar pictograficamente sentenças ditadas em língua de sinais. Contudo, quando solicitadas a registrarem pela escrita conteúdos ditados em língua portuguesa oral, as mesmas crianças passaram a empregar em suas produções letras convencionais do alfabeto, ainda que essas letras não mantenham relação de proximidade com o conteúdo ditado. Em outros termos, as crianças pesquisadas por Silva, espontaneamente, julgaram que a fala deve ser alfabeticamente representada e que a Libras exige uma representação escrita de natureza pictográfica.

Além do entendimento de que a língua de sinais não deve ser representada pela escrita alfabética, as crianças observadas por Silva (2008), embora não conhecessem o sistema de escrita de sinais, utilizaram para a representação de sentenças ditadas em Libras tentativas de escrita dos sinais. Desse modo, tais crianças, em diversas produções escritas, substituíram a representação figural do objeto ditado, ou seja, a escrita pictográfica pelo registro gráfico do significante, que corresponde à escrita dos sinais empregados pela professora surda que conduziu o ditado.

Em pesquisa recente, Wanderley (2012) destaca a possibilidade de melhor organização de textos, pelos surdos, a partir da escrita dos sinais. A pesquisadora apresenta a escrita de sinais como um sistema que permite que a apropriação da escrita pelo surdo ocorra de forma lúdica. 


\section{Conclusão}

A autonomia no uso da escrita pelo surdo é, provavelmente, o maior desafio que a educação bilíngue enfrenta hoje no Brasil. Os surdos brasileiros, em sua maioria, exibem dificuldades no uso da escrita alfabética, provavelmente em razão da enorme distância entre a língua de sinais, por meio da qual o surdo organiza o seu pensamento, e o sistema alfabético, criado para representação de línguas orais (SILVA; BOLSANELLO; SANDER, 2011). A despeito de tais dificuldades, a apropriação da escrita pelo surdo, como para qualquer aprendiz, é uma condição para a emancipação intelectual. Dessa forma, cabe aos educadores bilíngues a busca de caminhos alternativos, que favoreçam a conquista pelo surdo dessa ferramenta fundamental para sua humanização.

Nesse sentido, a escrita dos sinais, enquanto um sistema simbólico repleto de significados, parece constituir-se em uma possibilidade a mais, de conferir ao surdo condições maximizadas de desenvolvimento de suas funções superiores do pensamento, bem como de fornecer meios de aproximação com o sistema de escrita majoritário de seu país, que é a escrita alfabética.

É importante destacar que as duas formas de interpretação por educadores bilíngues, sobre as possíveis relações entre o surdo e a escrita, conforme apresentado nesse artigo, não devem ser tomadas como posições excludentes. Pesquisadores da neuropsicologia cognitiva afirmam que a escrita dos sinais é o caminho mais coerente para conferir ao surdo a condição efetiva de leitor e escritor. Indiscutivelmente, a escrita de sinais representa um ganho cultural, sem precedentes, na história dos surdos sinalizadores e essa ferramenta linguística não deve ser interpretada como obstáculo para a conquista, pelo surdo, de uma segunda língua, pela via da escrita, mas, pelo contrário, deve ser entendida como sistema simbólico capaz de promover aproximações entre diferentes línguas e diferentes sistemas de escrita.

Finalizando, não se pode deixar de comentar que, de acordo com H. Liu, C. Liu e Andrews (2014), fatores contextuais, culturais e linguísticos precisam ser considerados no entendimento de como crianças surdas usam a sua língua de sinais e constroem códigos de sinais no desenvolvimento de habilidades para aprenderem a ler e a escrever. 


\section{REFERÊNCIAS}

BOTELHO, Paula. Segredos e silêncios na educação dos surdos. Belo Horizonte: Autêntica, 1998.

BROCHADO, Sônia Maria Dechandt. A apropriação da escrita por crianças surdas usuárias da língua de sinais brasileira. Tese (Doutorado) - UNESP. Assis, 2003.

CAPOVILLA, Fernando César; RAPHAEL, Walkíria Duarte. Dicionário enciclopédico ilustrado trilíngue da língua de sinais brasileira. São Paulo: Edusp, 2001.

COSTA, Dóris Anita Freire. Lingüística e surdez: compreendendo a singularidade da produção escrita de sujeitos. Revista de Psicopedagogia, São Paulo, v. 20, n. 62, p. 94-106, 2003.

FERNANDES, Sueli. Educação bilíngüe para surdos: identidades, diferenças, contradições e mistérios. Tese (Doutorado) - UFPR. Curitiba, 2003.

FREIRE, Alice Maria da Fonseca. Aquisição do português como segunda língua: uma proposta de currículo para o Instituto Nacional de Educação de Surdos. In: SKLIAR, Carlos (Org.). Atualidade da educação bilingüe para surdos. Porto Alegre: Mediação, 1999. (v. 2).

GESUELI, Zilda M.; GÓES, Maria Cecília R. A língua de sinais na elaboração da criança surda sobre a escrita. Educação On-Line, nov. 2001. Disponível em: <http:// www.educacaoonline.pro.br/index.php?option=com_content\&view=article\&id=60:a-lingua-de-sinais-na-elaboracao-da-crianca-surda-sobre-a-escrita\&catid=5: educacao-especial\&Itemid=16>. Acesso em: 19/05/2014.

KARNOPP, Lodenir Becker. Língua de sinais na educação dos surdos. In: THOMA, Adriana da Silva; LOPES, Maura Corcini (Orgs.). A invenção da surdez: cultura, alteridade, identidade e diferença no campo da educação. Santa Cruz do Sul: EDUNISC, 2004.

LIU, Hsiu Tan; LIU, Chun Jung; ANDREWS, Jean F. Literacy and deaf students in Taiwan: issues, practices and directions for future research: part I. Deafness \& Education International, v. 16, n. 1, p. 2-22, mar. 2014.

SANCHES, Paola Beatriz. Possibilidades no ensino de português escrito como segunda lingua para alunos surdos: em discussão a metodologia de letramento bilíngue de Fernandes. 146 p. Dissertação (Mestrado em Educação) - Universidade Estadual de Maringá, Maringá, 2014.

SIGNWRITING. Writing Signed Languages. Disponível em: < http://www.signwriting. org > . Acesso em: 22/05/2014.

SILVA, Tânia dos Santos Alvarez. A aquisição da escrita pela criança surda desde a educação infantil. 227 p. Tese (Doutorado em Educação) - Setor de Educação, Universidade Federal do Paraná, Curitiba, 2008. 
SILVA, Tânia dos Santos Alvarez; BOLSANELLO, Maria Augusta; SANDER, Marieuza Endrissi. Perspectivas para o ensino da escrita de alunos surdos usuários de Libras. Teoria e Prática da Educação, Maringá, v. 14, n. 3, p. 35-41, set./dez. 2011.

STUMPF, Marianne Rossi. Transcrições de língua de sinais brasileira em sign writing. In: LODI, Ana Claudia B.; HARRISON, Kathryn M. P.; CAMPOS, Sandra. R. L.; TESKE, Ottmar (Orgs.). Letramento e Minorias. Porto Alegre: Mediação, 2003.

STUMPF, Marianne Rossi. Sistema Sign Writing: por uma escrita funcional para o surdo. In: THOMA, Adriana da Silva; LOPES, Maura Corcini (Orgs.). A invenção da surdez: cultura, alteridade, identidade e diferença no campo da educação. Santa Cruz do Sul: EDUNISC, 2004.

VYGOTSKY, Lev Semióvich. Fundamentos de defectología. In: Obras escogidas. Tomo V. Madrid: Visor, 1997.

VYGOTSKY, Lev Semióvich. A construção do pensamento e da linguagem. São Paulo: Martins Fontes, 2001.

WANDERLEY, Débora Campos. Aspectos da leitura e escrita de sinais: estudos de caso com alunos surdos da educação básica e de universitários surdos e ouvintes. 192 p. Dissertação (Mestrado em Linguística) - Universidade Federal de Santa Catarina, Florianópolis, 2012. 